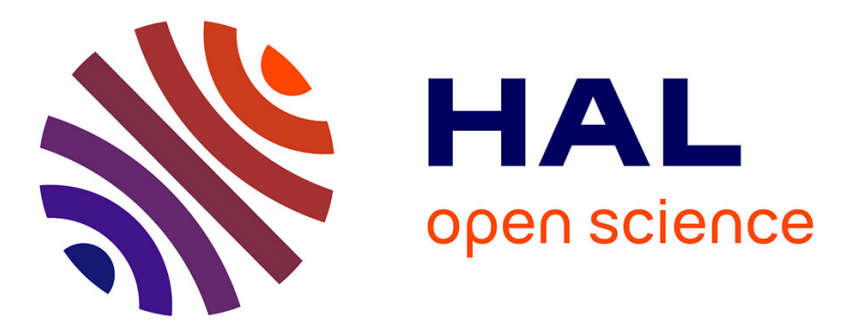

\title{
Quantifying phytoplankton communities using spectral fluorescence: the effects of species composition and physiological state
}

Nicolas Escoffier, Cécile Bernard, Sahima Hamlaoui, Alexis Groleau, Arnaud Catherine

\section{To cite this version:}

Nicolas Escoffier, Cécile Bernard, Sahima Hamlaoui, Alexis Groleau, Arnaud Catherine. Quantifying phytoplankton communities using spectral fluorescence: the effects of species composition and physiological state. Journal of Plankton Research, 2014, 37 (1), pp.233-247. 10.1093/plankt/fbu085 . insu-02886557

\section{HAL Id: insu-02886557 https://hal-insu.archives-ouvertes.fr/insu-02886557}

Submitted on 6 Nov 2020

HAL is a multi-disciplinary open access archive for the deposit and dissemination of scientific research documents, whether they are published or not. The documents may come from teaching and research institutions in France or abroad, or from public or private research centers.
L'archive ouverte pluridisciplinaire HAL, est destinée au dépôt et à la diffusion de documents scientifiques de niveau recherche, publiés ou non, émanant des établissements d'enseignement et de recherche français ou étrangers, des laboratoires publics ou privés. 


\title{
Journal of
}

\section{Quantifying phytoplankton communities using spectral fluorescence: the effects of species composition and physiological state}

\author{
NICOLAS ESCOFFIER ${ }^{1}$, GEGILE BERNARD ${ }^{2}$, SAHIMA HAMLAOUI $^{2}$, ALEXIS GROLEAU $^{1}$ AND ARNAUD GATHERINE $^{2 *}$ \\ 'ÉQUIPE DE GEOCHIMIE DES EAUX, UNIVERSITE PARIS DIDEROT, SORBONNE PARIS CITE, INSTITUT DE PHYSIQUE DU GLOBE DE PARIS, UMR 7 I 54 CNRS, F-75O I 3 \\ PARIS, FRANCE AND ${ }^{2}$ UMR 7245 MCAM MNHN-GNRS, EQUIPE CYANOBACTERIES, CYANOTOXINES ET ENVIRONNEMENT, MUSEUM NATIONAL D'HISTOIRE NATURELLE, \\ CASE 39, I 2 RUE BUFFON, F-7523 I PARIS CEDEX 05, FRANCE
}

*CORRESPONDING AUTHOR: arnocat@mnhn.fr

Received February 14, 2014; accepted September 8, 2014

Corresponding editor: Zoe Finkel

In situ fluorometers are the optimal means of providing high-frequency estimates of phytoplankton communities. However, they may be subjected to measurement biases originating from variations in the physiological states of cells, the use of spectral fluorescence signatures (SFS) defined on the basis of inappropriate phytoplankton groups and the lack of linear independence between selected sets of SFS. We assessed correction procedures for measurement biases in mono and mixed cultures of five freshwater phytoplankton species. We investigated the impacts of total Chl $a$ levels, the lack of linear independence between SFS and varying physiological states on the accuracy of the Chl $a$ estimates that were provided by the FluoroProbe (bbe Moldaenke GmbH, Germany). The use of species-specific SFS allowed for the correction of quantification and classification biases. In some cases, the procedure led to a lack of linear independence between SFS, which significantly reduced estimation accuracies. A convenient method to evaluate linear independence between SFS is provided. Differences in the physiological states of phytoplankton cultures following light pre-acclimation and/or N-starvation appeared to be species specific. Light pre-acclimation led to an underestimation of biomass (up to $-28.5 \%$ ) through fluorescence quenching. The responses of the phytoplankton cultures to $\mathrm{N}$-starvation varied depending on the species (from -40.3 to $+336 \%$ biases in Chl $a$ quantification). Overall, the application of appropriate corrective measures increased data accuracy. However, optimal data reliability can only be achieved by estimating phytoplankton community composition and associated environmental conditions.

KEYWORDS: fluoroprobe; spectral fluorescence; phytoplankton composition; linear independence; water monitoring 


\section{INTRODUGTION}

Following the adoption of the Water Framework Directive (EC, 2000), European countries are required to assess the state of aquatic ecosystems and to define management measures that guarantee their optimal ecological status. Phytoplankton communities are of paramount importance in the assessment of aquatic ecosystems (Spatharis and Tsirtsis, 2010) because they are related to ecosystems productivity and to eutrophication status (Reynolds and Petersen, 2000).

Traditional approaches for the estimation of phytoplankton biomass (e.g. chlorophyll $a$ extraction) by spectroscopy and community composition by microscopy (e.g. Utermöhlbased methods) are time-consuming and thus unsuitable for high-resolution data acquisition. Alternative methods that are based on differences in accessory pigments among phytoplankton taxonomic groups (Jeffrey and Vesk, 1997) have been proposed and include chemotaxonomic and spectrofluorometric methods. Among the chemotaxonomic methods, the CHEMTAX approach, which requires the HPLC analysis of pigment contents, is widely used (Mackey et al., 1996; Liu et al., 2012). However, it does not allow for high-resolution data acquisition. Spectrofluorometric methods enable low-cost, rapid measurements (Beutler et al., 2002; Richardson et al., 2010). These methods are derived from fluorescence-based chlorophyll $a(\mathrm{Chl} a)$ quantification methods that were proposed by several authors in the $1960 \mathrm{~s}$ and applied either in vitro (Yentsch and Menzel, 1963; Holm-Hansen et al., 1965) or in viwo to continuous measurements (Lorenzen, 1966; Yentsch and Yentsch, 1979; Yentsch and Phinney, 1985).

While some spectrofluorometric methods involve the measurement of fluorescence emission using phycobilins (Watras and Baker, 1988; Seppälä et al., 2007), the latest fluorometers measure the fluorescence excitation spectra of the photosystem II (PSII) core Chl $a$ following the selective excitation of antenna/accessory pigments at multiple wavelengths (Beutler et al., 2002). These fluorometers allow for the discrimination of four to six spectral groups (depending on the number of excitation wavelengths of the device) that are based on differences in accessory pigments among phytoplankton taxonomic groups (Johnsen and Sakshaug, 2007). Among these devices, the FluoroProbe (FP; bbe Moldaenke GmbH, Germany) enables the discrimination and quantification of four phytoplankton spectral groups (expressed in $\mu \mathrm{g}$ Chl $a \mathrm{~L}^{-1}$ ) following the excitation of accessory pigments at five wavelengths. For each taxonomic group, a mean spectral fluorescence signature (SFS) is defined based on analysis of multiple representative species.

Several studies have sought to assess the ability of the FP and its on-line version, the Algae Online Analyser
(AOA), to characterize phytoplankton communities in the field. The accuracies of FP estimations have been validated in rivers and reservoirs (Gregor and Maršálek, 2004; Izydorczyk et al., 2009). However, these studies used limited data sets involving ecosystems that exhibited low phytoplankton diversities and thus mainly assessed the ability of the FP to quantify the total phytoplankton Chla. Other data quality assessment studies that have used either the FP or the AOA have been performed on marine (Richardson et al., 2010; Goldman et al., 2013) and freshwater (Gregor et al., 2005; Catherine et al., 2012) samples. However, the FP data were compared either with CHEMTAX data or cell counts that were obtained using the Utermöhl method. It is well known that the CHEMTAX method may lead to biases in taxonomic classifications (Lewitus et al., 2005). In addition, the agreement between cell counts and the FP data may be masked by inter- and intra-specific variations in Chl $a$ cellular quota (MacIntyre et al., 2002) and cell biovolumes (Catherine et al., 2012) and also by the inability to quantify picophytoplankton using the Utermöhl method. Furthermore, due to the complexity of field samples, a comprehensive characterization of unexplained variances in correlations between methods is difficult to achieve (Catherine et al., 2012).

Measurement biases may lead to significant issues in terms of water monitoring, such as inappropriate estimates of in situ cyanobacteria blooms (Zamyadi et al., 2012). Among the factors that underlie these measurement biases, the impacts of the species compositions of natural phytoplankton assemblages and the physiological states of cells have long been recognized (Kiefer, 1973; Poryvkina et al., 1994). Working on pure cultures of marine species, MacIntyre et al. (MacIntyre et al., 2010) showed that the assumption of SFS being invariant within phytoplankton spectral groups (Beutler et al., 2002) is often violated. This originates from differences in pigment compositions between phytoplankton taxa of the same spectral groups and also to intraspecific variations in pigment quotas, for example, in response to light and nutrient availabilities. However, the impacts of such biases on FP (or AOA) data should also be assessed in mixed cultures because measurement error may vary depending on selected SFS combinations. Houliez et al. (Houliez et al., 2012) calibrated a new SFS for the discrimination of the marine Haptophyte Phaeocystis globosa and identified interferences due to the presence of other groups of microalgae that led to significant spectral group misclassifications.

Although informative, these results corresponded to specific case studies and did not allow for a comprehensive assessment of the limits of the FP algorithm with regard to the accurate deciphering of the species compositions of 
mixed assemblages. While these studies have provided novel insights into the impacts of varying physiological states on SFS in pure culture, neither of them tested the linear independence of newly defined SFS combinations or the potential biases originating from variations in physiological states in mixed assemblages.

In this study, we aimed to assess the relevance of applying species-specific calibrations to improve the ability of the FP to quantify total $\mathrm{Chl} a$ in five freshwater species representative of different spectral groups. We also examined the robustness of the corrections that were provided by the species-specific SFS depending on the total levels of Chl $a$, the variability in fluorescence emissions in relation to certain physiological states, such as those associated with light acclimation and/or nutrient stress and the species compositions of mixed assemblages. Their relative impacts were quantified and discussed in the context of the applicability of the FP data for environmental monitoring purposes. Lastly, we proposed a novel procedure for assessing the conditions under which newly defined signatures can be incorporated without inducing a lack of linear independence between SFS.

\section{METHOD}

\section{Gulture conditions}

Five clonal non-axenic freshwater microalgae and cyanobacteria strains were selected from the Paris Natural History Museum Collection of Cyanobacteria (PMG) and Eukaryotic Algae (ALCP) (Table I). The diatom Nitzschia palea (Kützing) W. Smith, the cryptophyte Cryptomonas tetrapyrenoidosa Skuja, the chlorophyte Pediastrum boryanum (Turpin) Meneghini and the cyanobacteria Limnothrix redekei (van Goor) Meffert and Planktothrix agardhii (Gomont) Anagnostidis and Komarek were selected based on their co-occurrences in freshwater lakes and rivers (Catherine et al., 2012). Each species was characterized by distinct PSII pigmentations (Table I) that corresponded with distinct pigment groups (PG; Johnsen and Sakshaug, 2007).
Pre-cultures were grown in stirred $1 \mathrm{~L}$ batches using specific growth media (Table I) and maintained in temperature-controlled growth chambers (KBW 4001, Binder, Germany) on a 16/8 h light/dark cycle using daylight fluorescent tubes (Lumilux ${ }^{\circledR}$, OSRAM, Germany). Light intensities were measured using a LI 190 Quantum Sensor (LiCor, Lincoln, USA).

Exponentially growing pre-cultures were used to inoculate $500 \mathrm{~mL}$ batch cultures with $200 \mathrm{~mL}$ of corresponding growth medium. For each treatment, the cultures were grown for 5 days in triplicate and were used for the SFS evaluations and mixture experiments. For the N-depleted conditions, the cultures were transferred into $\mathrm{N}$-free media after several washes. The depleted medium was obtained by replacing the $\mathrm{N}$-containing salts with $\mathrm{N}$-free salts (typically $\mathrm{NaNO}_{3}$ by $\mathrm{NaCl}_{2}$ ) to maintain the same ionic strength. The growth medium was buffered with MOPS to avoid any effect of $\mathrm{pH}$ variations between cultures. The N-depleted cultures were obtained after being grown for 6 days in the corresponding $\mathrm{N}$-free medium.

\section{Species-specific SFS definition}

\section{Fluoroprobe operating principle}

The functioning principle of the FP is detailed in Beutler et al. (Beutler et al., 2002). The FP measures the fluorescence that is emitted by the PSII core Chl $a$ following the sequential excitation of accessory pigments of the PSII antennae and provides estimates of total Chl $a\left(\mu \mathrm{g}\right.$ Chl $\left.a \mathrm{~L}^{-1}\right)$ in phytoplankton samples. Total Chl $a$ is then parsed among four phytoplankton groups on the basis of their fluorescence excitation spectra. To excite the accessory pigments, the FP uses five LEDs emitting at 470, 525, 570, 590 and $610 \mathrm{~nm}$. A sixth LED, which emits at $370 \mathrm{~nm}$, allows for the quantification of coloured dissolved organic matter and the correction of Chl $a$ estimates. Following the excitation of the accessory pigments, the fluorescence emission of Chl $a$ at $680 \mathrm{~nm}$ is measured by a photomultiplier that is positioned orthogonally to the LEDs.

Table I: Characteristics and growth conditions of the microalgae and cyanobacteria strains used in this study

\begin{tabular}{|c|c|c|c|c|c|c|c|}
\hline Species & Strain number & Class & Main accessory pigments & $\begin{array}{l}\text { Pigment } \\
\text { group }\end{array}$ & $\mathrm{T}\left({ }^{\circ} \mathrm{C}\right)$ & $\begin{array}{l}\text { Irradiance } \\
\left(\mu \mathrm{mol} \mathrm{m} \mathrm{m}^{-2} \mathrm{~s}^{-1}\right)\end{array}$ & Medium \\
\hline Nitzschia palea & ALCP 134.1 & Bacillariophyceae & fucoxanthin, chl $c_{1+2}$ & PG1 & 20 & 20 & DM2 \\
\hline Cryptomonas tetrapyrenoidosa & ALCP 147.1 & Cryptophyceae & phycobiliproteins, chl $c_{2}$ & PG12 & 20 & 20 & JM2 \\
\hline Pediastrum boryanum & ALCP 093.1 & Chlorophyceae & chl $b$ & PG9 & 25 & 30 & BB \\
\hline Limnothrix redekei & PMC 345.08 & Cyanophyceae & phycobiliproteins & PG13 & 25 & 20 & Z8 \\
\hline Planktothrix agardhii & PMC 532.08 & Cyanophyceae & phycobiliproteins & PG13 & 25 & 20 & Z8 \\
\hline
\end{tabular}

Pigment groups were defined according to Johnsen and Sakshaug (Johnsen and Sakshaug, 2007). DM2 and JM2 correspond to classical diatom medium (DM) and Jaworski medium (JM) in which $\mathrm{Ca}\left(\mathrm{NO}_{3}\right)_{2}$ and $\mathrm{NaNO}_{3}$ concentrations were doubled. 
In a first step, the FP is calibrated by using, as a reference, four SFS measured on cultures of species representative of each spectral phytoplankton group. The four spectral groups include the "green" algae (Chlorophyta and Euglenophyta) containing chlorophylls $a$ and $b$, the "blue" phycocyanin-rich algae (Cyanobacteria), the "brown" algae (Bacillariophyta, Dinophyta and Chrysophyta) containing chlorophylls $a$ and $c$ and xanthophylls (fucoxanthin and diadinoxanthin) and the "red" algae (Cryptophyta), which are rich in chlorophylls $a$ and $c$ and phycoerythrin (PE). In this study, these groups were, respectively, represented by $P$. boryanum, $P$ agardhii and $L$. redekei, $\mathcal{N}$. palea and $C$. tetrapyrenoidosa (Table I).

The identification of the phytoplankton composition of unknown samples is then obtained through an algorithm procedure, which compares the SFS measured on unknown samples to the SFS that serve as a reference. In brief, the bbe-FluoroProbe software is used to estimate the best sum of the four reference SFS to classify the total Chl $a$ concentrations among each group. The algorithm performs a linear unmixing of the four reference SFS to determine the best weighing factor to apply to the error sum calculation. The procedure differs from classical linear regression by taking into account the confidence envelope of SFS at each wavelength in the error sum calculation, which is reduced by an iterative procedure.

The FP operating principle relies on the following three assumptions: (i) the normed SFS are constant and thus independent of the physiological states of the cells or the strains that are considered within a given group, (ii) they are linearly independent and thus cannot be approximated by the weighted sums of the other spectral groups' SFS, and (iii) the normed spectra must be determined with sufficient accuracy (Beutler et al., 2002).

\section{SFS definition}

Species-specific SFS for the five selected phytoplankton species were obtained by estimating, for each LED, the slopes of the linear regressions between the Chla concentrations that were obtained from the pure stock cultures and the FP raw fluorescence data (in arbitrary units). Five calibration points were prepared that ranged from 5 to $200 \mu \mathrm{g} \mathrm{Chl} a \mathrm{~L}^{-1}$.

The Chl $a$ concentrations of the stock cultures were measured in triplicate using spectroscopy according to Talling and Driver (Talling and Driver, 1963) following $90 \%$ v/v methanol extractions (Catherine et al., 2012). The calibration curves were then prepared using successive dilutions. FP measurements were obtained for each calibration point after dark acclimation for $30 \mathrm{~min}$. Growth media measurements were also performed to subtract the corresponding offsets.
All of the measurements were obtained using a FP series 2 (bbe-Moldaenke GmbH, Schwentinental, Germany) that was equipped with the Workstation 25 (bbe-Moldaenke $\mathrm{GmbH}$, Schwentinental, Germany) to allow benchtop use of the device. This application requires smaller sample volumes $(25 \mathrm{~mL}$ ) and enables constant sample homogenization by stirring. Measurements were obtained every $2 \mathrm{~s}$ for $1 \min (n=30)$. The signal transmission exceeded $85 \%$ in every case, which was well above the $50 \%$ threshold that has been reported to decrease total Chl $a$ estimations by $5 \%$ (Beutler et al., 2002). The species-specific SFS were then normed to their respective maximum weighting coefficients.

\section{Impact of physiological state on SFS characterization}

To study the impacts of varying physiological states, the SFS were defined using $\mathrm{N}$-replete $(\mathrm{N}+)$ and $\mathrm{N}$-depleted $(\mathrm{N}-)$ cultures for each species. The effects of light acclimation on fluorescence emission were also investigated by defining new SFS (for both $\mathrm{N}+$ and $\mathrm{N}$ - conditions) from calibration points that were dark acclimated (DA) for $30 \mathrm{~min}$ (Maxwell and Johnson, 2000) or preacclimated (LA) for $2 \mathrm{~h}$ at species-specific growth irradiance levels (either 20 or $30 \mu \mathrm{mol} \mathrm{m}{ }^{-2} \mathrm{~s}^{-1}$ depending on the phytoplankton species; Table I). Species-specific SFS were thus defined using four experimental conditions $(\mathrm{N}+/ \mathrm{DA}, \mathrm{N}+/ \mathrm{LA}, \mathrm{N}-/ \mathrm{DA}$ and $\mathrm{N}-/ \mathrm{LA})$ with the $\mathrm{N}$-replete and dark-acclimated (N+/DA) treatment corresponding to the control treatment. The specific SFS corresponding to the control treatment was loaded (and the respective factory signature deactivated) to postcalibrate the data using the bbe-Fluoroprobe software.

\section{Species mixtures}

Potential Chla quantifications and classification biases were also investigated in binary mixtures of the five selected species. Each combination of species was assessed at two Chl $a$ levels (5 and $50 \mu \mathrm{g}$ Chl $a \mathrm{~L}^{-1}$ ) using three different mixtures of the two species (ca. 25/75, $50 / 50$ and $75 / 25 \%$ ) to check for threshold effects on FP performances. The different proportions of each mixture were sequentially prepared using stock cultures and measured by FP after being DA for $30 \mathrm{~min}$. The theoretical ratios of each species in the mixtures were calculated from the Chla concentrations of the stock cultures and the final dilution factors. Species mixture experiments were performed using $\mathrm{N}$-replete $(\mathrm{N}+)$ and $\mathrm{N}$-depleted $(\mathrm{N}-)$ cultures. In both cases, the theoretical values were compared with the post-calibrated FP data with the control $(\mathrm{N}+/ \mathrm{DA})$ species-specific SFS values. 


\section{Data analyses}

Data analyses were performed using the statistical environment $\mathrm{R}$ version 3.0.2 (R Development Core Team, 2013) and MATLAB (2012) (MathWorks, USA). The relationships between the spectroscopy Chl $a$ measurements and FP data were assessed using major axis type II linear regressions (R package "Imodel2"; Legendre, 2008). Deviations from the 1:1 theoretical relationship were tested using the R package "smart" (Warton et al., 2013).

To compare the factory-made and species-specific SFS, a similarity matrix that was based on Euclidean distance was defined and represented using a non-metric multidimensional scaling plot with the $\mathrm{R}$ package "MASS" (Ripley et al., 2013).

The linear independence of the factory-made and species-specific SFS was checked by the row reduction echelon form method using Gauss Jordan elimination with partial pivoting (MATLAB function "rref", Lindfield and Penny, 2012). The degree of linear independence was further studied using multivariate regression models that were based on non-negative least-squares restrictions (MATLAB function "Isqnonneg") on the weighting factors (Hu et al., 2010).

\section{RESULTS}

\section{Pure culture measurements}

\section{Total Chla quantifications}

For both the factory-made and species-specific SFS, the Pearson's association coefficients between Chl $a$ estimates by FP and spectroscopy were highly significant $(P<$ 0.001) for all of the N-replete cultures (Table II). These results confirmed the ability of FP to provide reliable fluorescence measurements within a range of total Chl $a$ concentrations from 5 to $200 \mu \mathrm{g} \mathrm{L}{ }^{-1}$. Interestingly, for all of the investigated species, the slope values that were obtained using factory settings departed significantly $(P<0.05)$ from the $1: 1$ theoretical relationship (Table II).
For the eukaryotic species and the cyanobacteria $L$. redekei, these values indicated underestimations of total Chl $a$ by the FP, while total Chl $a$ was overestimated for $P$ agardhii. Using control species-specific SFS allowed for the acquisition of slope values that were no longer significantly different $(P>0.05)$ from the 1:1 theoretical relationship (Table II).

\section{Spectral group classifications}

In addition to errors in total Chla quantification, biases in spectral group classifications were observed when factory settings were used (Table III). The level of misclassification to an incorrect spectral group depended on the degree to which a given control species-specific SFS differed from the corresponding factory-made SFS (Fig. 1). The SFS that was specific to $\mathcal{N}$. palea was situated outside of the tetrahedron formed by the four factory SFS and between the "brown" and "red" SFS. This translated to a $15.6 \pm 1.5 \%$ misclassification of total Chl $a$ towards the "red" group. Similarly, a pure culture of L. redekei was identified to be a binary mixture composed of "blue" and "red" algae $(67.8 \pm 2.1 \%$ towards the "red" group). Cryptomonas tetrapyrenoidosa was positioned inside of the tetrahedron and the corresponding Chl $a$ misclassification $(18.0 \pm 4.3 \%)$ was divided among the three remaining spectral groups ("brown", "blue" and "green", Table III). Pediastrum boryanum specific SFS was also located inside of the tetrahedron but was closest to the "green" SFS, leading to a smaller proportion of Chl $a$ misclassification $(7.8 \pm 3.1 \%)$. Lastly, . agardhii had a specific SFS that was nearly identical to the "blue" SFS and displayed only a marginal $(0.6 \pm 1.0 \%)$ classification bias towards the "red" group.

The use of species-specific SFS allowed for the correction of spectral group misclassifications $(<4 \%$ error; Table III). Surprisingly, the use of $P$. agardhii SFS led to slightly increased spectral group misclassifications (from $0.6 \pm 1$ to $3.2 \pm 2.9 \%$ ). The results that were obtained from both the factory and species-specific SFS indicated

Table II: Type II linear regression model results for the relationship between Chla levels that were estimated by spectroscopy $(\mathrm{n}=3)$ and $F P(\mathrm{n}=30)$ using factory or species-specific SFS as defined in the control conditions $(\mathcal{N}+/ D A)$

\begin{tabular}{|c|c|c|c|c|}
\hline \multirow[b]{2}{*}{ Species } & \multicolumn{2}{|l|}{ Factory SFS } & \multicolumn{2}{|l|}{ Species-specific SFS } \\
\hline & $\mathrm{FP}=\mathrm{f}\left(\mathrm{Chla}{ }_{-}\right.$extr $)$ & $R^{2}$ & $\mathrm{FP}=\mathrm{f}(\mathrm{Chla}$ extr) & $R^{2}$ \\
\hline Nitzschia palea & $y=0.465 x+1.212$ & 0.998 & $y=1.000 x+3.411$ & 0.998 \\
\hline Cryptomonas tetrapyrenoidosa & $y=0.486 x+1.188$ & 0.999 & $y=0.999 x+1.951$ & 0.999 \\
\hline Pediastrum boryanum & $y=0.864 x+2.102$ & 0.998 & $y=0.999 x+2.417$ & 0.997 \\
\hline Limnothrix redekei & $y=0.846 x+2.449$ & 0.998 & $y=1.001 x+2.621$ & 0.998 \\
\hline Planktothrix agardhii & $y=3.513 x+1.699$ & 0.998 & $y=1.005 x+0.344$ & 0.996 \\
\hline
\end{tabular}


Table III: Relative spectral group misclassifications of total Chla levels that were measured by the FP in monocultures using factory-made or species-specific SFS.

\begin{tabular}{|c|c|c|c|}
\hline Species & Calibration & Misclassification (\%) & Groups \\
\hline \multirow{2}{*}{ N.palea ("brown") } & Factory & $15.6 \pm 1.5$ & "red" \\
\hline & Specific & $3.4 \pm 3.0$ & "green" (3.3\%), "blue" (0.1\%) \\
\hline \multirow[t]{2}{*}{ C. tetrapyrenoidosa ("red") } & Factory & $18.0 \pm 4.3$ & "brown" (11\%), "blue" (6.8\%), "green" (0.2\%) \\
\hline & Specific & $3.0 \pm 2.6$ & "blue" (1.7\%), "green" (1.1\%), "brown" (0.2\%) \\
\hline \multirow[t]{2}{*}{ P. boryanum ("green") } & Factory & $7.8 \pm 3.1$ & "brown" (4.6\%), "blue" (1.7\%), "red" (1.5\%) \\
\hline & Specific & $2.5 \pm 2.9$ & "blue" (1.3\%), "brown" (1\%), "red" (0.2\%) \\
\hline \multirow[t]{2}{*}{ L. redekei ("blue") } & Factory & $67.8 \pm 2.1$ & "red" \\
\hline & Specific & $3.7 \pm 5.2$ & "red" \\
\hline \multirow[t]{2}{*}{ P. agardhii ("blue") } & Factory & $0.6 \pm 1.0$ & "red" \\
\hline & Specific & $3.2 \pm 2.9$ & "red" (2.1\%), "green" (0.7\%), "brown" (0.4\%) \\
\hline
\end{tabular}

Species-specific SFS were obtained under control conditions (N+/DA). Means \pm standard deviations were calculated from the five calibration dilutions ( $n=150$ measurements).

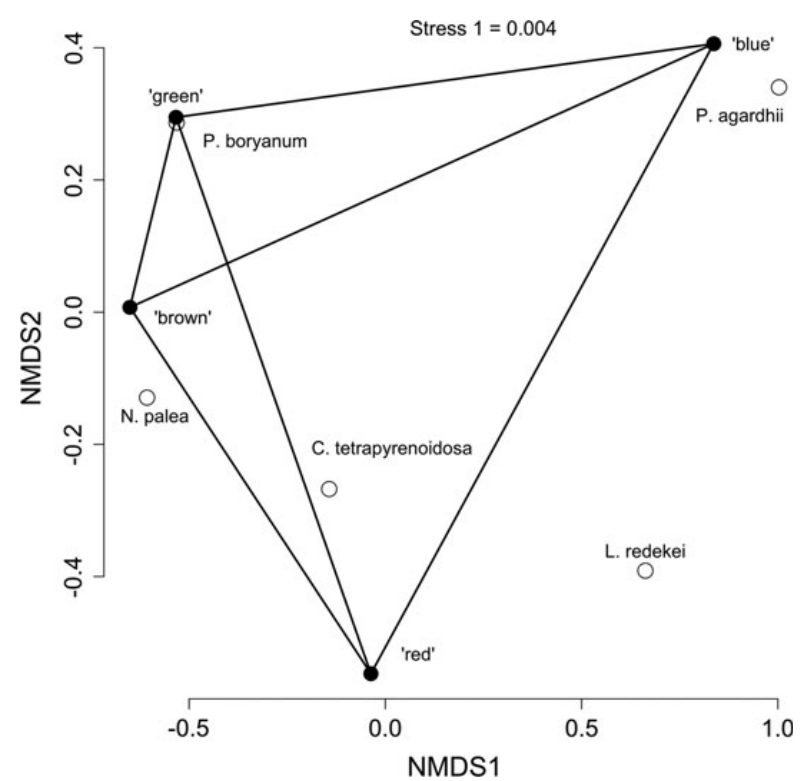

Fig. 1. Non-metric multidimensional scaling (NMDS) plot of normed factory and control (using N-replete, dark-acclimated cultures) species-specific SFS. Lines connecting the SFS of the different spectral groups define the reference tetrahedron within which linear unmixing was performed under factory settings. Stress value indicates minor distortion resulting from the ordination in two dimensions.

higher classification errors at the low Chla level of $5 \mu \mathrm{g}$ Chl $a \mathrm{~L}^{-1}$.

\section{Impact of physiological state (N-limitation and light acclimation)}

\section{Total Chla quantifications}

The pre-acclimation of the N-replete cultures to light $(\mathrm{N}+/ \mathrm{LA})$ resulted in an overall reduction in fluorescence emission (and thus to an underestimation of total Chl $a$ ) in all of the investigated species compared with the control DA cultures (Table IV). The Chl $a$ quantifications of the
P. agardhii cultures were only marginally impacted by the absence of dark acclimation $(-1.9 \%)$, and these results did not significantly differ from those of the control [i.e. the slope did not significantly $(P>0.05)$ differ from the 1:1 theoretical relationship]. The PE-rich species, $L$. redekei and $C$. tetrapyrenoidosa, were characterized by moderate underestimations $(-11.2$ and $-7.9 \%$, respectively) of total Chl $a$. The most pronounced effect was observed for $\mathcal{N}$. palea and P. boryanum $(-27.1$ and $-28.5 \%$, respectively).

The N-depleted conditions $(\mathrm{N}-)$ had much stronger effects on the Chl $a$ quantification errors than the lack of dark acclimation. Indeed, no marked differences were observed between the $\mathrm{N}-/ \mathrm{DA}$ and $\mathrm{N}-/ \mathrm{LA}$ conditions (Table IV). Following N-limitation, increased fluorescence emissions occurred for P. boryanum (19.6\%), N. palea $(99.1 \%)$ and $L$. redekei $(336.0 \%)$. An opposite trend was observed for $C$. tetrapyrenoidosa and $P$ agardhii, for which fluorescence emissions decreased by 40.3 and $17.4 \%$, respectively.

\section{Spectral group classifications}

The normed SFS for P. boryanum and P. agardhii were shown to be unaffected by N-depletion (Fig. 2A and D). Accordingly, no differences in spectral group classifications were observed compared with the control $(\mathrm{N}+/$ DA) conditions (see Supplementary data, Table SI). This was also true for $L$. redekei, although its normed SFS under N-depleted conditions indicated slightly decreased fluorescence emissions following excitation at 370, 470 and $610 \mathrm{~nm}$ (Fig. 2E). The impacts of N-depletion on the normed SFS for $\mathcal{N}$. palea and $C$. tetrapyrenoidosa were more pronounced (Fig. 2B and G) as they both exhibited markedly decreased fluorescence emissions after excitation at $525,570,590$ and $610 \mathrm{~nm}$. Indeed, the application of the respective control $(\mathrm{N}+/ \mathrm{DA})$ species-specific SFS for $\mathcal{N}$. palea and C. tetrapyrenoidosa led, respectively, to $17.4 \pm$ 2.8 and $22.6 \pm 1.4 \%$ total $\mathrm{Chl} a$ misclassifications 
Table IV: Impacts of light pre-acclimation and $\mathcal{N}$-depletion on the relationships between spectroscopic Chla estimates and FP Chla estimates using species-specific SFS as defined in the control conditions (using $\mathcal{N}$-replete dark-acclimated $(\mathcal{N}+/ D A)$ cultures $)$

\begin{tabular}{|c|c|c|c|c|}
\hline Species & Conditions & $\mathrm{FP}=\mathrm{f}(\mathrm{Chla}$ _extr $)$ & $R^{2}$ & $\Delta \_$Control $(\%)$ \\
\hline \multirow[t]{3}{*}{ N. palea } & $\mathrm{N}+/ \mathrm{LA}$ & $y=0.728 x-1.650$ & $1.000(<0.001)$ & -27.1 \\
\hline & $N-/ D A$ & $y=1.989 x-0.168$ & $0.997(<0.001)$ & 99.1 \\
\hline & $N-/ L A$ & $y=1.981 x-4.196$ & $0.997(<0.001)$ & 98.2 \\
\hline \multirow[t]{3}{*}{ C. tetrapyrenoidosa } & $\mathrm{N}+/ \mathrm{LA}$ & $y=0.920 x-1.531$ & $1.000(<0.001)$ & -7.9 \\
\hline & $N-/ D A$ & $y=0.596 x-0.776$ & $0.999(<0.001)$ & -40.3 \\
\hline & $N-/ L A$ & $y=0.567 x-2.246$ & $0.999(<0.001)$ & -43.2 \\
\hline \multirow[t]{3}{*}{ P. boryanum } & $\mathrm{N}+/ \mathrm{LA}$ & $y=0.714 x+3.201$ & $0.999(<0.001)$ & -28.5 \\
\hline & $N-/ D A$ & $y=1.194 x+0.569$ & $1.000(<0.001)$ & 19.6 \\
\hline & $N-/ L A$ & $y=1.419 x-2.297$ & $0.999(<0.001)$ & 42.2 \\
\hline \multirow[t]{3}{*}{ L. redekei } & $\mathrm{N}+/ \mathrm{LA}$ & $y=0.889 x+1.182$ & $1.000(<0.001)$ & -11.2 \\
\hline & $\mathrm{N}-/ \mathrm{DA}$ & $y=4.363 x-1.196$ & $0.997(<0.001)$ & 336.0 \\
\hline & $N-/ L A$ & $y=4.342 x-2.811$ & $0.997(<0.001)$ & 334.0 \\
\hline \multirow[t]{3}{*}{ P. agardhii } & $\mathrm{N}+/ \mathrm{LA}$ & $y=0.985 x+0.002$ & $1.000(<0.001)$ & -1.9 \\
\hline & $N-/ D A$ & $y=0.829 x-0.424$ & $0.999(<0.001)$ & -17.4 \\
\hline & $N-/ L A$ & $y=0.792 x-0.455$ & $1.000(<0.001)$ & -21.1 \\
\hline
\end{tabular}

The numbers in bracket correspond to the $P$-value of the statistical tests.

N, N-depleted; LA, light-acclimated.

towards the "green" group (Supplementary data, Table SI).

The acclimation of cultures (N-replete or N-depleted) to light did not introduce any variations of their normed SFS compared with those of the corresponding DA conditions (see Supplementary data, Figs S1 and S2).

\section{Assessment of binary phytoplankton mixtures}

Total Chla quantification

The FP performances in mixed binary conditions were evaluated by alternately replacing two of the four factorymade SFS with the corresponding species-specific SFS that were defined in the control conditions $(\mathrm{N}+/ \mathrm{DA})$. The deactivated factory-made SFS corresponded with the spectral groups of the investigated species. Under the control conditions, the FP data correlated well with the expected total Chla concentrations for all of the tested binary mixtures (Table $\mathrm{V}$ ), and the relative errors never exceeded $12 \%$ in cases of under- or overestimation. The maximum $\mathrm{Chl} a$ underestimation $(-11.8 \pm 8.0 \%)$ was obtained for the $P$. boryanum $/ L$. redekei mixture at the low Chl $a$ level ( $\left.5 \mu \mathrm{g} \mathrm{Chl} a \mathrm{~L}^{-1}\right)$. In contrast, the maximum Chl $a$ overestimation $(10.4 \pm 7.1 \%)$ was observed for the P. agardhii/N. palea mixture at the highest Chl $a$ level (50 $\mu \mathrm{g}$ Chl $\left.a \mathrm{~L}^{-1}\right)$. No relationship between total Chl $a$ level and relative quantification accuracy was observed.

Using the control ( $N+/ D A)$ species-specific SFS in the assessments of the $\mathrm{N}$-depleted mixed cultures led to limited total Chl $a$ quantification biases (Table V). In most cases, the relative error did not exceed 14\%. However, mixed assemblages were prepared based on the FP measurements of the stock cultures and not from the spectroscopic Chl $a$ estimates. Because the physiological states of the cells were demonstrated to impact the Chl $a$ quantifications in the pure cultures, this procedure corrected the inherent quantification errors that may have originated from nutrient stress. However, a noticeable exception $(46.1 \pm 22.2 \%$ misclassification) was found at the low Chl $a$ level $\left(5 \mu \mathrm{g}\right.$ Chl $\left.a \mathrm{~L}^{-1}\right)$ for the C. tetrapyrenoidosa/L. redekei mixture.

\section{Spectral group classifications}

Overall, under the control conditions, higher rates of misclassification were observed at the low Chla level of $5 \mu \mathrm{g}$ Chl $a \mathrm{~L}^{-1}$ (Fig. 3 and Table V). However, even at low levels, the relative spectral group misclassifications remained in the range of $\pm 13 \%$ in most cases (Fig. $3 \mathrm{~A}-$ F, I, J). Strong misclassifications were also found for the P. agardhii/N. palea and P. boryanum/L. redekei mixtures, including the underestimations of the relative Chl $a$ levels in $\mathcal{N}$. palea $(-26.9 \%$, Fig. $3 \mathrm{G}$ and Table $\mathrm{V})$ and P. boryanum $(-21.3 \%$, Fig. $3 \mathrm{H}$ and Table $\mathrm{V})$.

Although the row reduction echelon form (rref) tests concluded that the SFS combinations were linearly independent for all of the mixtures (data not shown), further investigations using multivariate regression analyses demonstrated that the degree of linear independence was variable depending on the SFS combinations that were considered (Table VI). Compared with the factory settings, some SFS combinations (e.g. $\mathcal{N}$. palea/C. tetrapyrenoidosa mixture) displayed high degrees of linear independence, which were associated with limited misclassifications under 

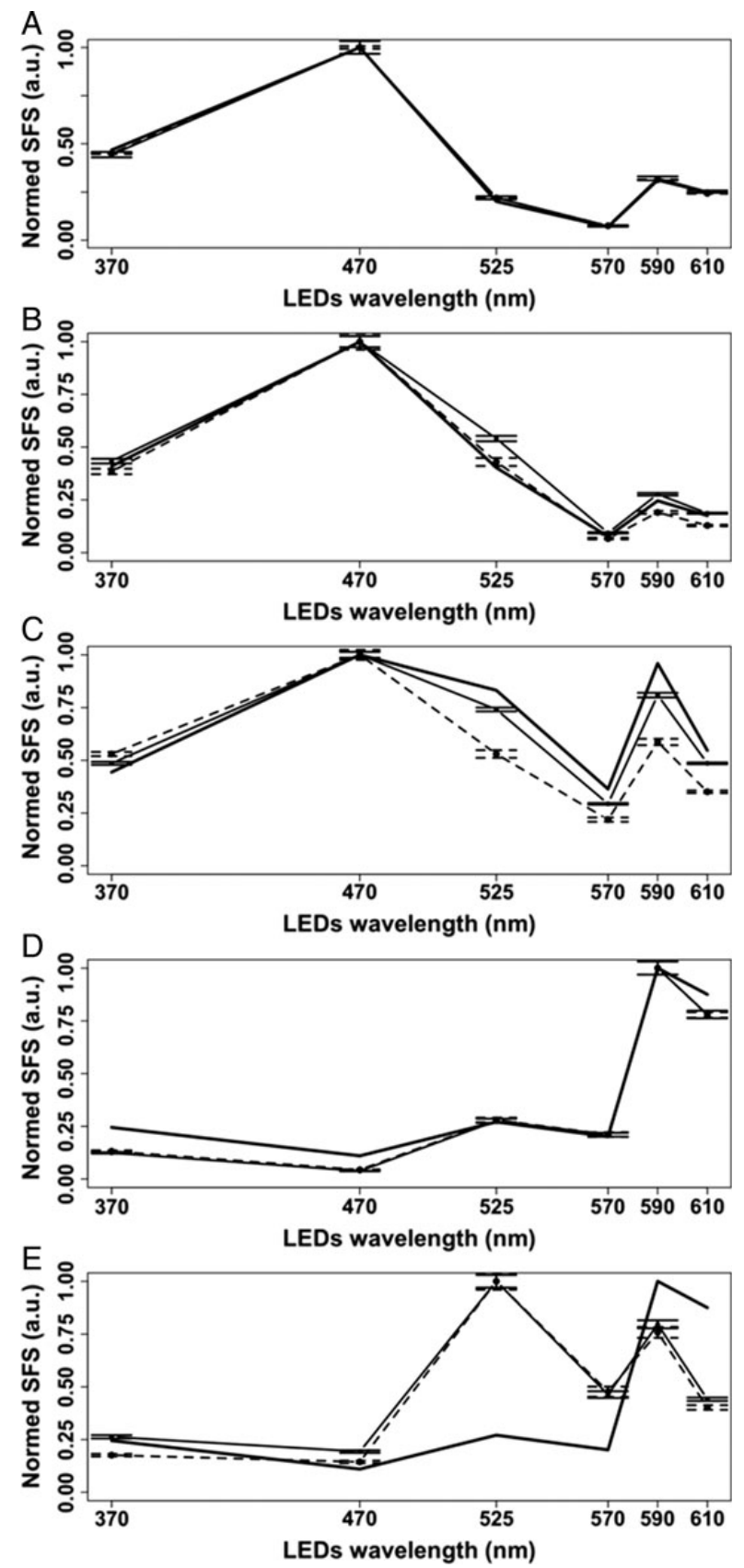

Fig. 2. Normed SFS (in arbitrary units) of N-replete (solid line) and $\mathrm{N}$-depleted (dashed line) dark-acclimated cultures of $(\mathbf{A})$ P. boryanum, $(\mathbf{B})$ $\mathcal{N}$. palea, $(\mathbf{G})$ C. tetrapyrenoidosa, $(\mathbf{D})$ P. agardhii and $(\mathbf{E})$ L. redekei. The normed factory SFS of the corresponding spectral groups is represented by a bold line. Error bars correspond to the standard deviations of the slope estimates of the regressions between Chla concentrations (by spectroscopy) and FP raw fluorescence data at each wavelength.

the control conditions $(\mathrm{N}+/ \mathrm{DA})($ Fig. 3B). In contrast, for the $P$. boryanum $/ L$. redekei and $P$ agardhii/ $\mathcal{N}$. palea mixtures, the SFS for the "red" group was well predicted $\left(R^{2}=\right.$ 0.919 and $R^{2}=0.865$, respectively; Table VI) by a weighted sum of these species' SFS, which led to strong spectral group misclassifications towards the "red" group (Fig. $3 \mathrm{G}$ and $\mathrm{H}$ ).

Under N-depleted conditions, the FP data displayed increased spectral group misclassifications compared with the control conditions. The observed errors appeared to be independent of the Chl $a$ levels that were considered (Fig. 3 and Table V). Overall, the strongest Chl $a$ misclassifications were found for the mixtures that contained either $\mathcal{N}$. palea or $C$. tetrapyrenoidosa. These results are concordant with the fact that their specific SFS were affected by N-depletion (Fig. 2), which increased their similarity to the SFS of the "green" group (data not shown) and explained the observed misclassifications towards either the "green" group or $P$. boryanum (Fig. 3A-D, F, G).

\section{DISGUSSION}

\section{Initial performances of FP and post-calibration}

Near-perfect correlations were revealed for the FP-derived estimations of the Chl $a$ concentrations of the monocultures using the factory settings (Pearson's $r>$ 0.997) for all of the investigated species (Table II). Thus, in our experimental conditions, all of the species displayed above-blank fluorescence measurements, and the fluorescence readings that were obtained by the FP were linear with regard to the $\mathrm{Chl} a$ levels that were measured by spectroscopy at concentrations of up to $200 \mu \mathrm{g} \mathrm{Chla}$ $\mathrm{L}^{-1}$. These results are consistent with those of Beutler et al. (Beutler et al., 2002), who defined $400 \mu \mathrm{g} \mathrm{Chl} a \mathrm{~L}^{-1}$ as the upper limit above which an algal solution is too dense to allow for proper signal transmission.

However, the slopes relating the $\mathrm{Chl} a$ estimates that were obtained using FP and spectroscopy fell below the $1: 1$ theoretical relationship in four of the five species ( $\mathcal{N}$. palea, C. tetrapyrenoidosa, P. boryanum and L. redekei), while the slope value of $P$ agardhii was 3.5 higher than the expected value (Table II). The observed differences may originate from the fact that the ratio of fluorescence emission per unit of Chla $\left(\mathrm{F}^{\mathrm{Chl}}\right)$ is known to be species dependent (Strickland, 1968) and the amounts of pigments that are associated with PSII vary greatly across species (Johnsen and Sakshaug, 2007). In addition, the Chl $a$ analysis method that was used to initially calibrate the FP may also have influenced the results. Indeed, the Chl $a$ extraction yield is known to be dependent on the extraction solvent, the species compositions of the samples (Papista et al., 2002) and the equations that were used to derive the Chl $a$ concentrations (Ritchie, 2006). 
N. ESCOFFIER ETAL. $\mid$ QUANTIFYING PHYTOPLANKTON USING SPEGTRAL FLUORESGENGE

Table V: Total Chla quantifications and classification errors in binary mixtures

\begin{tabular}{|c|c|c|c|}
\hline Mixture & Condition & $\Delta \_$Quantification (\%) & $\Delta \_$Classification (\%) \\
\hline \multirow[t]{4}{*}{ C. tetrapyrenoidosa/P. boryanum } & 5_Control & $0.0 \pm 8.5$ & $5.9 \pm 2.3$ \\
\hline & 50_Control & $7.4 \pm 9.1$ & $0.9 \pm 0.8$ \\
\hline & 5_N- & $5.4 \pm 4.6$ & $7.3 \pm 1.9$ \\
\hline & 50_N- & $1.6 \pm 5.7$ & $0.2 \pm 0.3$ \\
\hline \multirow[t]{4}{*}{ C. tetrapyrenoidosa/N. palea } & 5_Control & $4.1 \pm 7.9$ & $10.4 \pm 0.8$ \\
\hline & 50_Control & $1.5 \pm 5.1$ & $5.2 \pm 1.0$ \\
\hline & 5_N- & $0.7 \pm 7.9$ & $27.3 \pm 0.5$ \\
\hline & 50_N- & $-0.8 \pm 6.8$ & $24.3 \pm 1.9$ \\
\hline \multirow[t]{4}{*}{ C. tetrapyrenoidosa/L. redekei } & 5_Control & $9.2 \pm 5.1$ & $0.0 \pm 0.1$ \\
\hline & 50_Control & $7.0 \pm 8.4$ & $0.0 \pm 0.0$ \\
\hline & 5_N- & $46.1 \pm 22.2$ & $0.0 \pm 0.1$ \\
\hline & 50_N- & $-3.2 \pm 4.4$ & $16.7 \pm 10.3$ \\
\hline \multirow[t]{4}{*}{ C. tetrapyrenoidosa/P. agardhii } & 5_Control & $-6.8 \pm 9.2$ & $4.3 \pm 2.6$ \\
\hline & 50_Control & $6.6 \pm 8.0$ & $2.9 \pm 1.0$ \\
\hline & 5_N- & $-13.7 \pm 19.2$ & $25.8 \pm 5.1$ \\
\hline & $50 \_\mathrm{N}-$ & $-3.7 \pm 10.5$ & $24.6 \pm 4.7$ \\
\hline \multirow[t]{4}{*}{ L. redekei/N. palea } & 5_Control & $-5.4 \pm 4.8$ & $9.6 \pm 2.6$ \\
\hline & 50_Control & $7.1 \pm 9.7$ & $1.1 \pm 0.6$ \\
\hline & 5_N- & $-2.8 \pm 8.6$ & $15.8 \pm 0.3$ \\
\hline & 50_N- & $1.9 \pm 7.1$ & $0.8 \pm 1.3$ \\
\hline \multirow[t]{4}{*}{ P. boryanum/N. palea } & 5_Control & $4.2 \pm 4.0$ & $4.4 \pm 1.8$ \\
\hline & 50_Control & $3.7 \pm 7.8$ & $0.0 \pm 0.0$ \\
\hline & 5_N- & $6.6 \pm 6.1$ & $0.8 \pm 1.4$ \\
\hline & 50_N- & $2.8 \pm 4.8$ & $0.0 \pm 0.0$ \\
\hline \multirow[t]{4}{*}{ P. agardhii/N. palea } & 5_Control & $6.5 \pm 8.7$ & $18.3 \pm 8.3$ \\
\hline & 50_Control & $10.4 \pm 7.1$ & $8.1 \pm 1.0$ \\
\hline & 5_N- & $10.7 \pm 8.3$ & $31.3 \pm 1.2$ \\
\hline & 50_N- & $8.2 \pm 2.6$ & $28.6 \pm 1.6$ \\
\hline \multirow[t]{4}{*}{ P. boryanum/L. redekei } & 5_Control & $-11.8 \pm 8.0$ & $30.6 \pm 2.4$ \\
\hline & 50_Control & $2.3 \pm 3.5$ & $5.0 \pm 0.8$ \\
\hline & $5 \_\bar{N}-$ & $-14.0 \pm 5.0$ & $31.6 \pm 7.8$ \\
\hline & 50_N- & $-6.4 \pm 5.0$ & $12.3 \pm 10.1$ \\
\hline \multirow[t]{4}{*}{ P. agardhii/L. redekei } & 5_Control & $-1.2 \pm 8.5$ & $4.1 \pm 1.9$ \\
\hline & 50_Control & $3.3 \pm 10.4$ & $0.4 \pm 0.6$ \\
\hline & 5_N- & $-4.5 \pm 7.0$ & $6.4 \pm 1.1$ \\
\hline & 50_N- & $-2.8 \pm 5.4$ & $0.0 \pm 0.0$ \\
\hline \multirow[t]{4}{*}{ P. agardhii/P. boryanum } & 5_Control & $0.0 \pm 7.5$ & $2.2 \pm 1.3$ \\
\hline & 50_Control & $7.0 \pm 4.4$ & $1.0 \pm 0.9$ \\
\hline & 5_N- - & $4.7 \pm 3.0$ & $0.0 \pm 0.0$ \\
\hline & 50_N- & $5.6 \pm 4.3$ & $0.0 \pm 0.0$ \\
\hline
\end{tabular}

acclimation. Means \pm standard deviations were calculated from the three mixtures ratios of two species for each condition.

With regard to spectral group misclassifications in mono or mixed suspensions, higher error rates were always observed at the lowest Chla level that was tested $\left(5 \mu \mathrm{g} \mathrm{Chl} a \mathrm{~L}^{-1}\right)$, which was previously reported by Twiss et al. (Twiss et al., 2012). In addition, the performance of the FP was dependent upon the species that was being considered (Table III). Indeed, the factory SFS that were originally included in the FP software correspond with mean signatures that were obtained from various species considered as representative of the four spectral groups (Beutler et al., 2002). MacIntyre et al. (MacIntyre et al., 2010) showed that species within spectral groups display some variability in their SFS, which depends on PSII antenna pigmentation (Johnsen and Sakshaug, 2007). The degrees of similarity between the species-specific and factory-made SFS will thus be a determinant factor impacting the accuracy of FP data when using factory settings. Because the signatures integrate a confidence envelope at each wavelength, even slight deviations from the mean group SFS can lead to spectral group misclassifications (Table III). In this study, the most striking example was observed for $L$. redekei, which showed a $67.8 \pm 2.1 \%$ misclassification in favour of the "red" group, confirming previous observations (Beutler et al., 2004; Catherine et al., 2012). Limnothrix redekei is a PE-rich cyanobacteria (Suda et al., 2002) that thus displays an intermediate SFS between the "blue" and "red" groups (Fig. 1). Some species (P. boryanum and P. agardhii) showed very little differences when compared with the factorymade SFS (Figs 1 and 2), leading to almost perfect spectral group classifications (Table III). Nitzschia palea and C. tetrapyrenoidosa displayed moderate Chla misclassifications, which mainly biased the measures towards the "red" and "brown" spectral groups, respectively. 


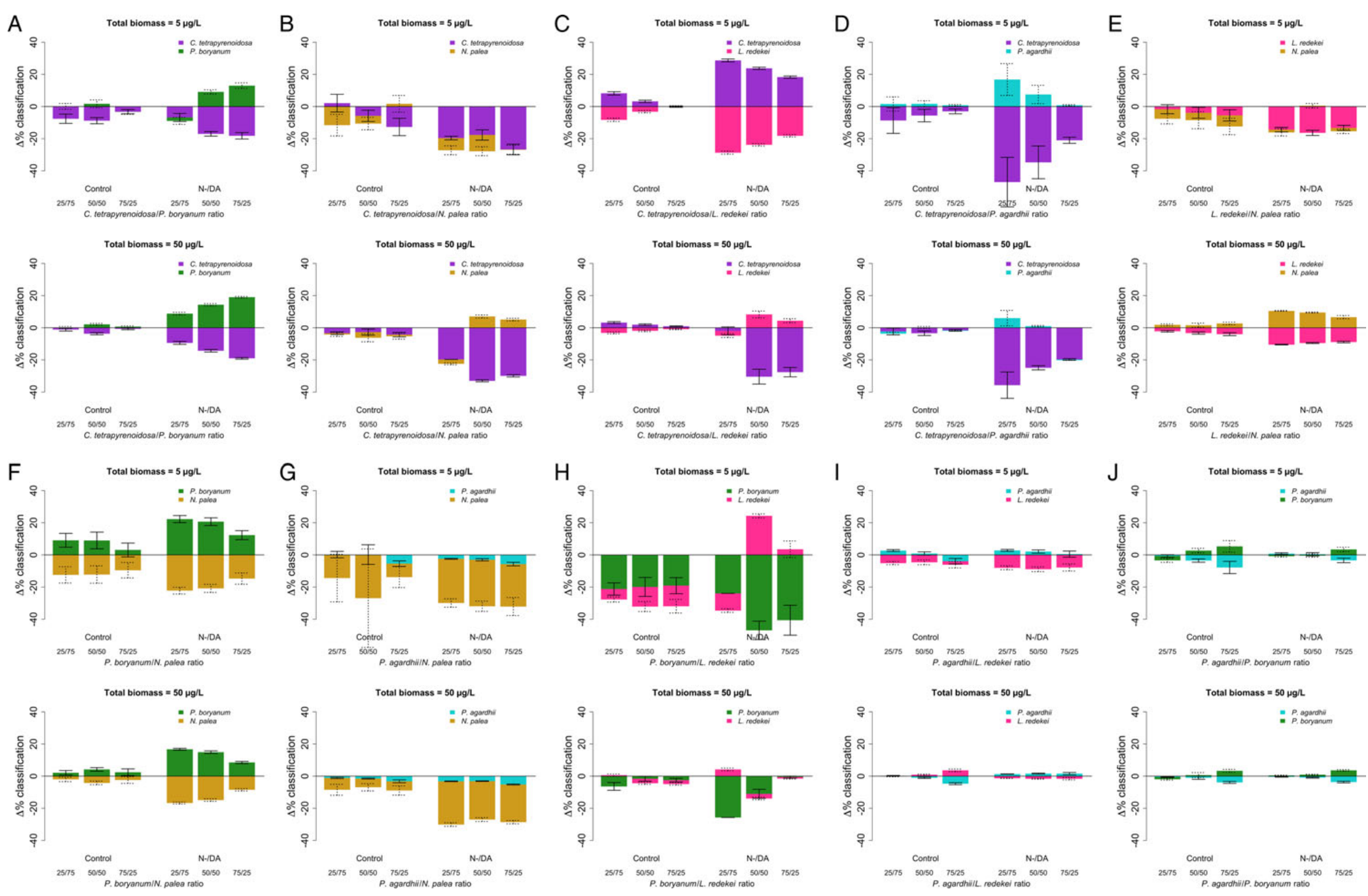

Fig. 3. Relative errors $(\Delta \%)$ of spectral group classifications within mixtures $(\mathbf{A})$ C. tetrapyrenoidosa/P. boryanum, (B) C. tetrapyrenoidosa/N. palea, $(\mathbf{C})$ C. tetrapyrenoidosa/L. redekei, (D) C. tetrapyrenoidosa/P.

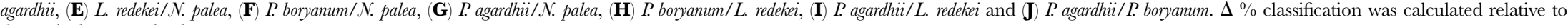
theoretical expected values. 
N. ESCOFFIER ETAL. $\quad$ QUANTIFYING PHYTOPLANKTON USING SPEGTRAL FLUORESGENGE

Table VI: Weighted coefficients obtained from multivariate linear regression model outputs of selected factory-made and control $(\mathcal{N}+/ D A)$ species-specific SFS combinations

\begin{tabular}{|c|c|c|c|c|c|c|c|c|c|c|}
\hline Selected SFS combinations & "green" & "blue" & "brown" & "red" & L. redekei & P. boryanum & N. palea & C. tetra. & P. agardhii & $R^{2}$ \\
\hline "green" & - & 0.065 & 0.946 & 0.000 & - & - & - & - & - & 0.918 \\
\hline "blue" & 0.000 & - & 0.000 & 0.603 & - & - & - & - & - & 0.028 \\
\hline "brown" & 0.873 & 0.000 & - & 0.085 & - & - & - & - & - & 0.914 \\
\hline "red" & 0.000 & 0.629 & 0.992 & - & - & - & - & - & - & 0.675 \\
\hline N. palea & 0.687 & 0.000 & - & - & - & - & - & 0.267 & - & 0.851 \\
\hline C. tetrapyrenoidosa & 0.000 & 0.470 & - & - & - & - & 0.979 & - & - & 0.901 \\
\hline "green" & - & 0.051 & - & - & - & - & 0.880 & 0.000 & - & 0.812 \\
\hline "blue" & 0.000 & - & - & - & - & - & 0.000 & 0.624 & - & 0.000 \\
\hline L. redekei & - & - & 0.000 & 0.714 & - & 0.000 & - & - & - & 0.098 \\
\hline P. boryanum & - & - & 0.960 & 0.016 & 0.000 & - & - & - & - & 0.915 \\
\hline "brown" & - & - & - & 0.000 & 0.061 & 0.947 & - & - & - & 0.930 \\
\hline "red" & - & - & 0.000 & - & 0.715 & 0.838 & - & - & - & 0.919 \\
\hline N. palea & 0.763 & - & - & 0.199 & - & - & - & - & 0.000 & 0.838 \\
\hline P. agardhii & 0.000 & - & - & 0.556 & - & - & 0.000 & - & - & 0.041 \\
\hline "green" & - & - & - & 0.000 & - & - & 0.892 & - & 0.033 & 0.805 \\
\hline "red" & 0.000 & - & - & - & - & - & 1.004 & - & 0.627 & 0.865 \\
\hline
\end{tabular}

All of the species-specific SFS reduced the percentages of misclassifications to incorrect algal groups to below $4 \%$ (Table III) and allowed for the correction of the slopes relating the FP data to the spectroscopic estimates (Table II). These corrections were also assessed using binary assemblages under the control conditions $(\mathrm{N}+/ \mathrm{DA})$, and the $\mathrm{FP}$ was shown to correctly estimate total Chl $a$ with a relative error of $\pm 12 \%$ (Table V). Moreover, in most cases, the use of species-specific SFS reduced classification biases to $\pm 13 \%$, even when mixing $L$. redekei with another PE-containing species, such as C. tetrapyrenoidosa (Fig. 3 and Table V). In similar binary mixtures of $P$ globosa with marine diatoms or cryptophytes, Houliez et al. (Houliez et al., 2012) observed higher errors in spectral group classifications compared with our results. However, the authors calibrated the device using a combination of factory and species-specific SFS, despite having demonstrated the limits of factory-made SFS to correctly estimate pure cultures. In addition, they did not check the linear independence of the corresponding set of SFS, and this procedure, according to the data that were presented in this study, appears to be central to the validation of the use of newly defined signatures. Indeed, despite the fact that the rref analysis did not identify any linear dependence between the SFS (factorymade and/or species-specific), some configurations that were used in this study were shown to be inappropriate by multivariate regression approaches and led to reduced FP performances (Fig. $3 \mathrm{G}$ and $\mathrm{H}$; see later in this section).

\section{SFS dependence on physiological variability}

\section{Light fluorescence pathways}

Overall, light acclimation for the $\mathrm{N}$-replete cultures $(\mathrm{N}+/ \mathrm{LA})$ resulted in the underestimation of Chla levels when compared with the control DA conditions
(Table IV). Given that light acclimation did not induce any changes in the shape of SFS, this underestimation originated from variations in the magnitudes of $\mathrm{F}^{\mathrm{chl}}$, and more specifically, on the balance of excitation energy that was used in photochemistry or dissipated by fluorescence or by other dissipative pathways (MacIntyre et al., 2010). Because the FP uses saturating light pulses, the variations that were observed between the measurements obtained following DA $\left(\mathrm{F}_{\mathrm{m}}\right.$ or maximum fluorescence in darkacclimated state) or $\mathrm{LA}\left(\mathrm{F}_{\mathrm{m}}{ }^{\prime}\right.$ or maximum fluorescence in light-acclimated state) treatments may reflect changes in the efficiency of the non-photochemical quenching (NPQ) of fluorescence (Maxwell and Johnson, 2000). The NPQ corresponds to excess energy dissipation as heat. This mechanism prevents the structural damaging of the photosystems (PS) reaction centres originating from the production of reactive oxygen species when the electron transport chain is saturated (Asada, 2006). Nitzschia palea and $P$. boryanum were the most susceptible species to these effects, showing similar reductions in fluorescence that may have been associated with xanthophylls cycle activity (Demmig-Adams, 1990). In comparison, C. tetrapyrenoidosa, $L$. redekei and $P$. agardhii showed moderate reductions in their fluorescence emissions under LA conditions. These species display different NPQ mechanisms (Schubert et al., 1995; Campbell et al., 1998; Kaňa et al., 2012) that are probably related to the fact that these species are adapted to low-light conditions (Gervais, 1998; Reynolds and Petersen, 2000). These results emphasize the need to perform FP measurements following dark acclimation, particularly under field conditions in which irradiance may be much higher and significantly impact FP data accuracy (Serra et al., 2009). When fluorometers, such as the FP, are used for real-time in situ monitoring, diel $\mathrm{F}^{\mathrm{chl}}$ variability should also be considered 
because it may lead to day-night variations in fluorescence emissions (Dandonneau and Neveux, 1997). When dark acclimation cannot be performed, concurrent PSII photochemical yield estimations may be used to adjust for the effects of NPQ on chlorophyll fluorescence (Chekalyuk and Hafez, 2011).

\section{Impacts of nutrient stress on fluorescence measurements} $\mathrm{N}$-depletion, which was characterized by a lack of growth of corresponding cultures, was shown to produce varying effects, depending on the species in consideration, on the magnitude and spectral dependence of $F^{\text {chl }}$. These effects may result from variations in the absolute and relative quantities of light harvesting pigments, the energy transfer efficiencies towards PSII and the amounts of energy that are used in the photochemistry reactions or dissipated by fluorescence or quenching (Beutler et al., 2002; MacIntyre et al., 2010). Indeed, compared with the control conditions, $\mathrm{N}$-depletion resulted in strong Chl $a$ estimations and classification biases. The $\mathrm{N}$-depleted cultures of $\mathcal{N}$. palea and L. redekei exhibited marked increases (approximately two to four times) of $\mathrm{F}^{\mathrm{chl}}$, while these effects were less pronounced for P. boryanum (Table IV). Increased $\mathrm{F}^{\text {chl }}$ levels in response to environmental stresses (N-depletion in particular) have been previously reported (Kiefer, 1973; Kruskopf and Flynn, 2007; MacIntyre et al., 2010), and our data matched the reported amplitudes. However, we also found that some species (C. tetrapyrenoidosa and P. agardhii) showed reductions (40.3 and $17.4 \%$, respectively) in $\mathrm{F}^{\mathrm{chl}}$ following $\mathrm{N}$-depletion (Table IV). Despite the opposite responses that were observed with some species (either increased or decreased $\mathrm{F}^{\mathrm{chl}}$ ), these findings may reflect reductions in photochemical efficiencies following nutrient stress. In some cases, these reductions may be related to the downregulation of pigment synthesis or to structural damage to PSII, which both would reduce energy transfer to the core Chl $a$ (Geider et al., 1997). This was likely the case for the $\mathcal{N}$. palea and C. tetrapyrenoidosa normed SFS (Fig. 2), for which $\mathrm{N}$-depletion induced reductions in fluorescence emission after excitations at 525 and $590-610 \mathrm{~nm}$. A possible hypothesis is that the reduced fluorescence emission may originate from alterations in the fucoxanthin/Chla ratio in $\mathcal{N}$. palea (Hou et al., 2007) and in the PE/Chla ratio (Sciandra et al., 2000) in C. tetrapyrenoidosa. Increased $F^{\text {chl }}$ may, in some cases, partially compensate for the decreased pigment contents (Kruskopf and Flynn, 2007) and explain the varying responses that were observed among the species following $\mathrm{N}$-depletion.

The SFS shape, in the $470-570 \mathrm{~nm}$ range, is critical for the differentiation of eukaryotic species (MacIntyre et al., 2010). The observed modifications in the SFS shape of $\mathcal{N}$. palea and C. tetrapyrenoidosa made them more similar to the "green" SFS, thus reducing their degrees of linear independence. Accordingly, in the binary mixtures of these two species, all of the misclassified Chla was directed towards the "green" group (or P. boryanum) at both Chl $a$ levels that were tested (Fig. 3). The relative consistency of the SFS of $P$. agardhii, $P$. boryanum and $L$. redekei (Fig. 2) likely originates from the lower sensitivity of these species to $\mathrm{N}$-depletion. Resistance to $\mathrm{N}$ limitation may originate from the storage of $\mathrm{N}$ as cyanophicin granules in Cyanobacteria (Kolodny et al., 2006), while the corresponding mechanisms remain unclear for $P$. boryanum. Regarding $L$. redekei, the changes in SFS likely originated from phycobilisome degradation.

\section{Spectral fluorescence methods and implications for environmental monitoring}

The necessity of applying specific calibrations to overcome some of the FP limitations originating from factory calibrations was confirmed. First, it allows for a better agreement of the FP data with the Chl $a$ quantification reference methods (e.g. spectroscopy). Additionally, it provides more consistent estimates for those species whose corresponding factory settings lead to classification biases (Leboulanger et al., 2002). However, the selection of a given set of SFS may perfectly correlate with the results of the reference methods in some cases but may also produce erroneous data due to successions in the composition of communities and the occurrence of species with different spectral properties. Thus, discrete samples remain necessary to track changes that may occur in the composition of phytoplankton communities (e.g. by conventional microscopy-based methods).

In addition, newly defined SFS should not blindly be applied in FP without testing for linear independence between the SFS combinations. Although all of the combinations that were tested in this study were considered to be linearly independent by conventional rref tests, multivariate regression models identified some associations that lacked linear independence and resulted in reduced FP performances (Fig. 3H and Table VI). Such interferences were shown to be more problematic under low Chl $a$ conditions and illustrate FP algorithm limits to accurately estimate the spectral groups' compositions of samples displaying weak fluorescence signals. This may be critical for health risk assessments in relation to cyanobacteria blooms, especially if the FP data are compared with local guidelines (Zamyadi et al., 2012). It also brings the quality of the FP data into question for ecosystems that are characterized by low total phytoplankton 
biomass, such as marine ecosystems or oligotrophic lakes and rivers. Because the FP data can be post-calibrated, users should implement the proposed multivariate regression approach to validate the use of new SFS associations and apply the combinations ensuring maximum linear independence. If linear independence cannot be achieved, then the FP estimates should be considered with caution. Because the FP uses a least squares-based approach to deconvolute the fluorescence spectra, the number of spectral groups that can be discriminated is dependent upon the number of excitation wavelengths of the device. The spectral group classification may be biased even in the presence of slight collinearities between selected SFS. The addition of excitation wavelengths could thus be beneficial, especially in the $470-$ $570 \mathrm{~nm}$ range, because it would improve the spectral resolution of eukaryotic species, such as diatoms and dinoflagellates. In addition, alternative fluorescence spectra analysis methods that are based on factorial regressions, such as the partial least square analysis, are less sensitive to SFS collinearity and could also be implemented (Seppälä and Olli, 2008). Alternatively, the multivariate processing of raw fluorescence measurements (e.g. using a principal component analysis; Alexander et al., 2012) can be used to identify the dominant fluorescence spectra of mixed phytoplankton assemblages. However, the fluorescence spectra (and thus the corresponding spectral groups) that are identified using such a method may correspond with quite heterogeneous phytoplankton mixtures (Alexander et al., 2012).

Finally, our results have confirmed that $\mathrm{F}^{\mathrm{chl}}$ is impacted by the physiological states of cells, which strictly violates the SFS constancy assumption. Changes in the magnitude of $\mathrm{F}^{\mathrm{chl}}$ due to varying physiological states (e.g. following short-term responses to light stress) would result in quantification errors (under-estimation). In addition, some physiological stresses (e.g. $\mathrm{N}$ starvation) may lead to changes in both the magnitude and spectral dependence of $\mathrm{F}^{\mathrm{chl}}$, which may induce varying degrees of Chl $a$ quantification and classification errors depending on the species under consideration. The results that are presented in this study correspond with extreme laboratory conditions, which are rarely encountered in the field. Previous field studies have indeed reported fair relationships between FP Chl $a$ estimates and biomass data that have been obtained using reference methods (Catherine et al., 2012). Certainly, Chl $a$ cannot be strictly considered as a measure of biomass (Kruskopf and Flynn, 2007), which is usually estimated based on biovolume or carbon (C) data. However, a strong covariance between fluorescence and biomass estimates may be achieved if the dynamic range of the fluorescence signal is higher than the range of intra- and interspecific variability in Chl $a$ per unit of carbon or biovolume (approximately one order of magnitude), which is likely to be the prime determinant of $\mathrm{F}^{\mathrm{chl}}$ (MacIntyre et al., 2010). Alternatively, tracking of changes in fluorescence emission per unit of Chl $a$ could also be used as a convenient indicator of physiological stress in phytoplankton.

\section{GONGLUSIONS}

This study demonstrates that the FP represents an efficient method for the quantification of phytoplankton Chl $a$ and community composition and that the application of specific calibrations greatly improves the agreement of the FP data with those of the reference methods.

However, the robustness of the corrections that are provided by calibrations may be subjected to some biases that users must be aware of when using the probes' data. In this context, complementary sampling is indeed necessary for identifying phytoplankton community successions and selecting appropriate sets of SFS. A novel procedure is also proposed to assess the linear independence of the selected SFS sets.

In this sense, a library of species-specific signatures would also be highly desirable. However, it is currently impossible to apply signatures that have been obtained from a given fluorometer in the calibration process of another due to hardware differences. Further work should aim at overcoming this limitation to allow for the interoperability of species-specific SFS.

Keeping these limitations in mind, fluorescence-based tools, such as the FP, remain unparalleled for achieving the high spatial/temporal coverage of phytoplankton community dynamics.

\section{SUPPLEMENTARY DATA}

Supplementary data can be found online at http://plankt. oxfordjournals.org.

\section{AGKNOWLEDGEMENTS}

The authors thank Claude Yéprémian for his advice on algal culturing techniques and Charlotte Duval for providing the Paris Museum Collection strains. The authors are also grateful to three reviewers for their useful comments.

\section{FUNDING}

This work was funded by the ANR CEP\&S 2010 PULSE and R2DS 2010 CarboSeine research programs and also supported through a CIFRE grant awarded to N.E. by Nke Instrumentation. 


\section{REFERENGES}

Alexander, R., Gikuma-Njuru, P. and Imberger, J. (2012) Identifying spatial structure in phytoplankton communities using multiwavelength fluorescence spectral data and principal component analysis. Limnol. Oceanogr. Methods, 10, 402-415.

Asada, K. (2006) Production and scavenging of reactive oxygen species in chloroplasts and their functions. Plant Physiol., 141, 391-396.

Beutler, M., Wiltshire, K. H., Meyer, B. et al. (2002) A fluorometric method for the differentiation of algal populations in vivo and in situ. Photosynth. Res., 72, 39-53.

Beutler, M., Wiltshire, K. H., Reineke, C. et al. (2004) Algorithms and practical fluorescence models of the photosynthetic apparatus of red cyanobacteria and Cryptophyta designed for the fluorescence detection of red cyanobacteria and cryptophytes. Aquat. Microb. Ecol., 35, $115-129$.

Campbell, D., Hurry, V., Clarke, A. K. et al. (1998) Chlorophyll fluorescence analysis of cyanobacterial photosynthesis and acclimation. Microbiol. Mol. Biol. Rev., 62, 667-683.

Catherine, A., Escoffier, N., Belhocine, A. et al. (2012) On the use of the FluoroProbe (R), a phytoplankton quantification method based on fluorescence excitation spectra for large-scale surveys of lakes and reservoirs. Water Res., 46, 1771-1784.

Chekalyuk, A. and Hafez, M. (2011) Photo-physiological variability in phytoplankton chlorophyll fluorescence and assessment of chlorophyll concentration. Opt. Express, 19, 22643-22658.

Dandonneau, Y. and Neveux, J. (1997) Diel variations of in vivo fluorescence in the eastern equatorial Pacific: an unvarying pattern. Deep-Sea Res. II, 44, 1869- 1880.

Demmig-Adams, B. (1990) Carotenoids and photoprotection: a role for the xanthophyll zeaxanthin. Biochim. Biophys. Acta, 1020, 1-24.

EC. (2000) European Commission Directive 2000/60/EC of the European Parliament and of the council of 23 October 2000 establishing a framework for Community action in the field of water policy. Off. F. Eur. Commun., L327: 1-72.

Geider, R. J., MacIntyre, H. L. and Kana, T. M. (1997) Dynamic model of phytoplankton growth and acclimation: responses of the balanced growth rate and the chlorophyll a:carbon ratio to light, nutrientlimitation and temperature. Mar. Ecol. Prog. Ser, 148, 187-200.

Gervais, F. (1998) Ecology of cryptophytes coexisting near a freshwater chemocline. Freshwater Biol., 39, 61-78.

Goldman, E. A., Smith, E. M. and Richardson, T. L. (2013) Estimation of chromophoric dissolved organic matter (CDOM) and photosynthetic activity of estuarine phytoplankton using a multiple-fixedwavelength spectral fluorometer. Water Res., 47, 1616-1630.

Gregor, J., Geriš, R., Maršálek, B. et al. (2005) In situ quantification of phytoplankton in reservoirs using a submersible spectrofluorometer. Hydrobiologia, 548, 141-151.

Gregor, J. and Maršálek, B. (2004) Freshwater phytoplankton quantification by chlorophyll a: a comparative study of in vitro, in vivo and in situ methods. Water Res., 38, 517-522.

Holm-Hansen, O., Lorenzen, C. J., Holmes, R. W. et al. (1965) Fluorometric determination of chlorophyll. f. Cons. Int. Explor. Mer, 30, $3-15$.

Hou, J. J., Huang, B. Q., Cao, Z. R. et al. (2007) Effects of nutrient limitations on pigments in T. weissflogii and $P$. donghaiense. F. Integr. Plant Biol., 49, 686-697.
Houliez, E., Lizon, F., Thyssen, M. et al. (2012) Spectral fluorometric characterization of Haptophyte dynamics using the FluoroProbe: an application in the eastern English Channel for monitoring Phaeocystis globosa. F. Plankton Res., 34, 136-151.

Hu, X., Su, R., Zhang, F. et al. (2010) Multiple excitation wavelength fluorescence emission spectra technique for discrimination of phytoplankton. 7. Ocean Univer. China, 9, 16-24.

Izydorczyk, K., Carpentier, G., Mrówczyński, J. et al. (2009) Establishment of an alert level framework for cyanobacteria in drinking water resources by using the Algae Online Analyser for monitoring cyanobacterial chlorophyll a. Water Res., 43, 989-996.

Jeffrey, S. W. and Vesk, M. (1997) Introduction to marine phytoplankton and their pigment signatures. In Jeffrey, S. W., Mantoura, R. F. C. and Wright, S. W. (eds), Phytoplankton Pigments in Oceanography: Guidelines to Modern Methods. UNESCO Publishing, Paris.

Johnsen, G. and Sakshaug, E. (2007) Biooptical characteristics of PSII and PSI in 33 species (13 pigment groups) of marine phytoplankton, and the relevance for pulse-amplitude-modulated and fast-repetitionrate fluorometry. F. Phycol., 43, 1236-1251.

Kaňa, R., Kotabová, E., Sobotka, R. et al. (2012) Non-photochemical quenching in Cryptophyte alga Rhodomonas salina is located in chlorophyll a/c antennae. PLoS ONE, 7, e29700.

Kiefer, D. A. (1973) Chlorophyll $a$ fluorescence in marine centric diatoms: responses of chloroplasts to light and nutrient stress. Mar: Biol., 23, 39-46.

Kolodny, N. H., Bauer, D., Bryce, K. et al. (2006) Effect of nitrogen source on cyanophycin synthesis in Synechocystis sp. Strain PCC 6308. f. Bacteriol., 188, 934-940.

Kruskopf, M. and Flynn, K. J. (2007) Chlorophyll content and fluorescence responses cannot be used to gauge reliably phytoplankton biomass, nutrient status or growth rate. New Phytol., 169, 525-536.

Leboulanger, C., Dorigo, U., Jacquet, S. et al. (2002) Application of a submersible spectrofluorometer for rapid monitoring of freshwater cyanobacterial blooms: a case study. Aquat. Microb. Ecol., 30, 83-89.

Legendre, P. (2008) lmodel2: Model II Regression. R Package version 1.6-3.

Lewitus, A. J., White, D. L., Timowski, R. G. et al. (2005) Adapting the CHEMTAX method for assessing phytoplankton taxonomic composition in Southeastern US. Estuaries, 28, 160-172.

Lindfield, G. R. and Penny, J. E. T. (2012) Numerical Methods using Matlab $^{\circledR}, 3$ rd edn. Academic Press. 525 pp.

Liu, X., Huang, B., Liu, Z. et al. (2012) High-resolution phytoplankton diel variations in the summer stratified central Yellow Sea. 7. Oceanogr., 68, 913-927.

Lorenzen, C. J. (1966) A method for the continuous measurement of in vivo chlorophyll concentration. Deep-Sea Res., 13, 223-227.

MacIntyre, H. L., Kana, T. M., Anning, T. et al. (2002) Photoacclimation of photosynthesis irradiance response curves and photosynthetic pigments in microalgae and cyanobacteria. F. Phycol., 38, $17-38$.

MacIntyre, H. L., Lawrenz, E. and Richardson, T. L. (2010) Taxonomic discrimination of phytoplankton by spectral fluorescence. In Suggett, D. J. et al. (eds), Chlorophyll a Fluorescence in Aquatic Sciences: Methods and Applications, Developments in Applied Phycology, vol. 4. Springer, Dordrecht pp. 129-169.

Mackey, M., Mackey, D., Higgins, H. et al. (1996) CHEMTAX-a program for estimating class abundances from chemical markers: 


\section{N. ESCOFFIER ETAL. $\mid$ QUANTIFYING PHYTOPLANKTON USING SPEGTRAL FLUORESGENGE}

application to HPLC measurements of phytoplankton. Mar. Ecol. Prog. Ser, 144, 265-283.

MATLAB Version 8.0. Natick, Massachusetts: The MathWorks Inc., 2012.

Maxwell, K. and Johnson, G. N. (2000) Chlorophyll fluorescence-a practical guide. F. Exp. Bot., 51, 659-668.

Papista, E., Ásc, E. and Böddi, B. (2002) Chlorophyll-a determination with ethanol - a critical test. Hydrobiologia, 485, 191-198.

Poryvkina, L., Babichenko, S., Kaitala, S. et al. (1994) Spectral fluorescence signatures in the characterization of phytoplankton community composition. F. Plankton Res., 16, 1315-1327.

R Development Core Team. (2013) R: A Language and Environment for Statistical Computing. R Foundation for Statistical Computing, Vienna. http://www.R-project.org.

Reynolds, C. S. and Petersen, A. C. (2000) The distribution of planktonic Cyanobacteria in Irish lakes in relation to their trophic state. Hydrobiologia, 424, 91-99.

Richardson, T. L., Lawrenz, E., Pinckney, J. L. et al. (2010) Spectral fluorometric characterization of phytoplankton community composition using the Algae Online Analyser ${ }^{\circledR}$. Water Res., 44, $2461-2472$.

Ripley, B., Venables, B., Bates, D. M. et al. (2013) MASS: functions and datasets to support Venables and Ripley, 'Modern Applied Statistics with S' (4th edition, 2002). Springer, New York, R Package version 27.3-29.

Ritchie, R. J. (2006) Consistent sets of spectrophotometric chlorophyll equations for acetone, methanol and ethanol solvents. Photosynth. Res., 89, $27-41$.

Schubert, H., Forster, R. M. and Sagert, S. (1995) In situ measurement of state transition in cyanobacterial blooms: kinetics and extent of the state change in relation to underwater light and vertical mixing. Mar Ecol. Prog. Ser., 128, 99-108.

Sciandra, A., Lazzara, L., Claustre, H. et al. (2000) Responses of growth rate, pigment composition and optical properties of Cryptomonas sp. to light and nitrogen stresses. Mar. Ecol. Prog. Ser., 201, 107-120.

Seppälä, J. and Olli, K. (2008) Multivariate analysis of phytoplankton spectral in vivo fluorescence: estimation of phytoplankton biomass during a mesocosm study in the Baltic Sea. Mar. Ecol. Prog. Ser., 370 69-85.
Seppälä, J., Ylöstalo, P., Kaitala, S. et al. (2007) Ship-of-opportunity based phycocyanin fluorescence monitoring of the filamentous cyanobacteria bloom dynamics in the Baltic Sea. Estuar. Coast. Shelf Sci., 73, 489-500.

Serra, T., Borrego, G., Quintana, X. et al. (2009) Quantification of the effect of nonphotochemical quenching on the determination of in vivo chl a from phytoplankton along the water column of a freshwater reservoir. Photochem. Photobiol., 85, 321-331.

Spatharis, S. and Tsirtsis, G. (2010) Ecological quality scales based on phytoplankton for the implementation of Water Framework Directive in the Eastern Mediterranean. Ecol. Indic., 10, 840-847.

Strickland, J. D. H. (1968) Continuous measurement of in viwo chlorophyll: a precautionary note. Deep-Sea Res., 15, 225-227.

Suda, S., Watanabe, M. M., Otsuka, S. et al. (2002) Taxonomic revision of water-bloom-forming species of oscillatorioid cyanobacteria. Int. F. Syst. Evol. Micr., 52, 1577-1595.

Talling, J. F. and Driver, D. (1963) In Doty, M. (eds), Proceedings on Primary Production Measurement, Marine and Freshwater. US Atomic Energy Engineering Commission, Hawaii, pp. 142-146.

Twiss, M. R., Ulrich, C., Zastepa, A. et al. (2012) On phytoplankton growth and loss rates to microzooplankton in the epilimnion and metalimnion of Lake Ontario in mid-summer. 7. Great Lakes Res., 38, $146-153$.

Warton, D., Duursma, R., Falster, D. et al. (2013) smatr: Major Axis Estimation and testing routines. R Package version 3.4-3.

Watras, G. J. and Baker, A. L. (1988) Detection of planktonic cyanobacteria by tandem in vivo fluorometry. Hydrobiologia, 169, 77-84.

Yentsch, C. S. and Menzel, D. W. (1963) A method for the determination of phytoplankton chlorophyll and phaeophytin by fluorescence. Deep-Sea Res., 10, 221-231.

Yentsch, C. S. and Phinney, D. A. (1985) Spectral fluorescence - an ataxonomic tool for studying the structure of phytoplankton populations. F. Plankton Res., 7, 617-632.

Yentsch, G. S. and Yentsch, C. M. (1979) Fluorescence spectral signatures-characterization of phytoplankton populations by the use of excitation and emission spectra. 7. Mar. Res., 37, 471-483.

Zamyadi, A., McQuaid, N., Dorner, S. et al. (2012) Cyanobacterial detection using in viwo fluorescence probes: managing interferences for improved decision making. JAWWA, 104, 466-479. 